\title{
A novel submicron emulsion system loaded with vincristine-oleic acid ion-pair complex with improved anticancer effect: in vitro and in vivo studies
}

\author{
This article was published in the following Dove Press journal: \\ International Journal of Nanomedicine \\ 19 March 2013 \\ Number of times this article has been viewed
}

\section{Ting Zhang' \\ Yong Zheng ${ }^{2}$ \\ Qiang Peng ${ }^{3}$ \\ $\mathrm{Xi} \mathrm{Cao}$ \\ Tao Gong' \\ Zhirong Zhang}

'Key Laboratory of Drug Targeting and Drug Delivery Systems, Sichuan University, Chengdu, People's Republic of China; ${ }^{2}$ Second Affiliated Hospital,

Chongqing Medical University,

Chongqing, People's Republic

of China; ${ }^{3}$ State Key Laboratory

of Oral Diseases, Sichuan University,

Chengdu, People's Republic of China
Correspondence: Tao Gong

Key Laboratory of Drug Targeting, Ministry of Education, Sichuan University,

17 Section 3 Southern Renmin Road,

Chengdu 6I004I, People's Republic

of China

Tel +86288550 I6I5

$\mathrm{Fax}+86288550 \quad 1615$

Email gongtaoy@126.com
Background: Vincristine (VCR), which is a widely used antineoplastic drug, was integrated with a submicron-emulsion drug-delivery system to enhance the anticancer effect.

Methods: After the formation of a VCR-oleic acid ion-pair complex (VCR-OA), the VCR-OAloaded submicron emulsion (VCR-OA-SME), prepared by classical high-pressure homogenization, was characterized and its in vitro anticancer effects were evaluated.

Results: The submicron-emulsion formulation exhibited a homogeneous round shape. The mean particle size, zeta potential, and encapsulation efficiency were $157.6 \pm 12.6 \mathrm{~nm},-26.5 \pm 5.0 \mathrm{mV}$ and $78.64 \% \pm 3.44 \%$, respectively. An in vitro release study of the VCR-OA-SME revealed that $12.4 \%$ of the VCR was released within the first 2 hours (initial burst-release phase) and the rest of the drug was detected in the subsequent sustained-release phase. Compared with VCR solution, the pharmacokinetic study of VCR-OA-SME showed relatively longer mean residence time (mean residence time $[0-\infty]$ increased from 187.19 to 227.56 minutes), higher maximum concentration (from $252.13 \mathrm{ng} / \mathrm{mL}$ to $533.34 \mathrm{ng} / \mathrm{mL}$ ), and greater area under the curve (area under the curve $[0-\infty]$ from $11,417.77 \mu \mathrm{g} / \mathrm{L} /$ minute to $17,164.34 \mu \mathrm{g} / \mathrm{L} /$ minute. Moreover, the VCR-OA-SME exhibited higher cytotoxicity $(P<0.05)$ on tumor cells by inducing cell arrest in the $\mathrm{G}_{2} / \mathrm{M}$ phase or even apoptosis $(P<0.05)$.

Conclusion: The VCR-OA-SME formulation in our study displayed great potential for an anticancer effect for VCR.

Keywords: ion-pair complex, submicron emulsion, cytotoxicity, apoptosis, cell uptake

\section{Introduction}

Vincristine (VCR, Figure 1A), isolated from the leaves of the periwinkle plant Catharanthus roseus, ${ }^{1}$ is a widely used antineoplastic drug in the clinic, especially for pediatric and adult malignancies. ${ }^{2}$ It is a cell cycle-specific anticancer drug that mainly interferes with mitotic spindle microtubules ${ }^{3-7}$ and induces tumor cell apoptosis. ${ }^{7-9}$ In the past few decades, optimizing the formulation and then improving its anticancer effect has attracted much attention. The investigated formulation includes microemulsions, ${ }^{10}$ common nanoparticles, ${ }^{11}$ conventional liposomes, ${ }^{12}$ sterical liposomes, ${ }^{13}$ and targeted nanoparticles. ${ }^{14}$ The clinical applications of the above carriers are largely limited by their complex components and/or complicated production process. Therefore, it is necessary to develop a VCR vehicle with higher anticancer effects. Emulsion is a commonly acceptable formulation that has been used in clinics for years, and microemulsion ${ }^{15-17}$ and submicron emulsion ${ }^{18,19}$ have been studied extensively. These vehicles can be administered via 

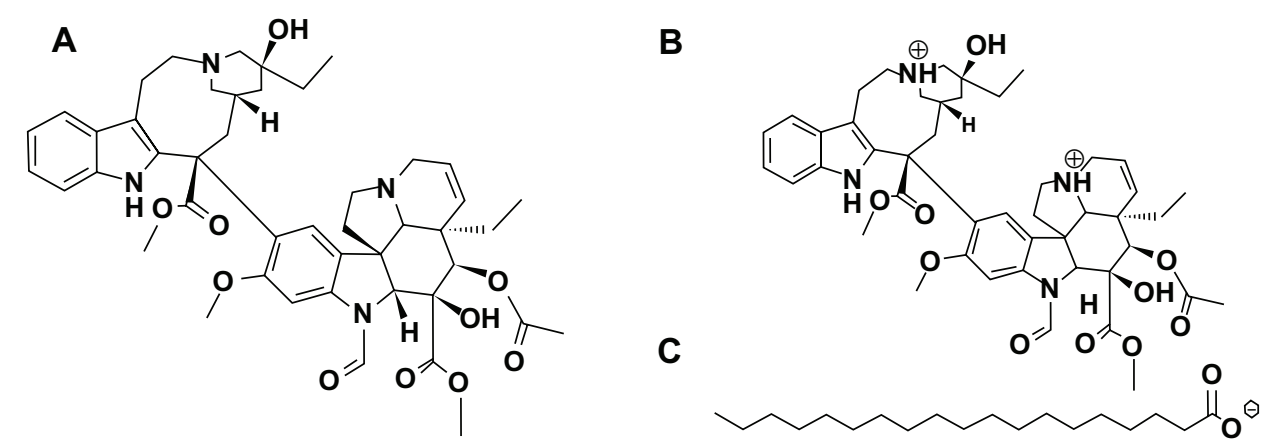

Figure I Chemical structure of vincristine $(\mathbf{A})$, ionized vincristine $(\mathbf{B})$, and oleic acid (C).

Note: Two tertiary nitrogen atoms in the structure of vincristine can be ionized, and one carboxyl group in the structure of oleic acid can be negatively charged under certain circumstances.

parenteral, ${ }^{10,20}$ transdermal, ${ }^{19}$ and ocular ${ }^{21}$ routes. Wang et al prepared a micron emulsion to carry VCR, ${ }^{10}$ which was stable and exhibited greater antitumor effect. However, this formulation contained a special component poly(ethylene glycol)distearoyl phosphatidylethanolamine that largely increased the cost of preparation and caused some side effects after repeated administrations, such as accelerated blood clearance. ${ }^{22-25}$ What's more, the possible mechanism of the improved anticancer effect was still unclear at the cellular level.

The aim of this study was to prepare a novel and intravenously injectable submicron emulsion drug delivery system loaded with a VCR-oleic acid (OA) ion complex. In order to encapsulate sulfate salt of VCR into emulsion drops, VCR-OA was constructed to improve the lipophilicity, and then VCR-OA was loaded into a submicron emulsion (SME) by the conventional high-pressure homogenization method. After that, the physicochemical characterizations of VCROA-SME were analyzed. The in vitro features, including release profile, in vitro anticancer effect, which included growth inhibition, mitosis disturbance, and cell-apoptosis induction, were measured. Its in vivo pharmacokinetic properties and the possible mechanisms of the increasing anticancer effect were also studied.

\section{Materials and methods}

\section{Materials}

VCR was purchased from Guangzhou Hanfang Pharmaceutical (Guangzhou, People's Republic of China). OA was kindly offered by Lipoid (Ludwigshafen, Germany). Soybean phospholipid was provided by Shanghai Tai-Wei Pharmaceutical (Shanghai, People's Republic of China). Solutol HS15 (polyoxyethylene esters of 12-hydroxystearic acid) was generously offered by BASF People's Republic of China (Shanghai, People's Republic of China). Soybean oil was bought from Beiya Medical Oil (Tieling, People's
Republic of China). Vitamin C, butylated hydroxyanisole, trypsin, 3-(4,5-dimethyl thiazol-2-yl)-2,5-diphenltetrazolium bromide (MTT), and 4'6-diamidino-2-phenylindole (DAPI) were obtained from Sigma-Aldrich (St Louis, MO, USA). A Pierce bicinchoninic acid protein assay kit and an annexin V-fluorescein isothiocyanate (V-FITC) apoptosis kit were bought from Thermo Fisher Scientific (Waltham, MA, USA) and Nanjing KeyGen Biotechnology (Nanjing, People's Republic of China), respectively. All other chemicals were of analytical grade or better.

\section{Tumor cell line and cell culture}

The MCF-7 cell line was provided by Shanghai Institutes for Biological Sciences (Shanghai, People's Republic of China) and cultured in Roswell Park Memorial Institute 1640 medium containing penicillin (100 IU/mL), streptomy$\operatorname{cin}(100 \mu \mathrm{g} / \mathrm{mL})$, and $10 \%$ fetal bovine serum (FuMeng Gene, Shanghai, People's Republic of China). Cells were maintained in a humidified atmosphere containing $5 \% \mathrm{CO}_{2}$ at $37^{\circ} \mathrm{C}$.

\section{Animals}

All healthy male Wistar rats were purchased from the Laboratory Animal Center of Sichuan University (Chengdu, People's Republic of China), and all animal experiments were supervised by the Institutional Animal Care and Ethics Committee of Sichuan University. Each group of five rats was fed in one cage, with free access to standard rat chow and water in wellcontrolled conditions $\left(25^{\circ} \mathrm{C} \pm 1^{\circ} \mathrm{C}, 55 \%\right.$ air humidity $)$. The rats were acclimatized for at least 5 days before study use.

\section{Methods of vincristine quantification Quantification of the in vitro samples}

The VCR was quantified by high-performance liquid chromatography (HPLC). Briefly, ethanol was added to disrupt the emulsion, and $20 \mu \mathrm{L}$ of the resulting transparent solution was 
injected into an HPLC system (Agilent 1260; Agilent Technologies, Santa Clara, CA, USA). A Kromasil C18 reverse phase column $(150 \times 4.6 \mathrm{~mm}, 5 \mu \mathrm{m}$; AkzoNobel, Separation Products, Bohus, Sweden) and the mobile phase consisting of acetonitrile and 0.01 $\mathrm{M} \mathrm{NaH}_{2} \mathrm{PO}_{4}$ (55/45, V/V, pH 7.0, adjusted with triethylamine) were used to separate the targeted component. The samples were eluted by mobile phase at a flow rate of $1.0 \mathrm{~mL} /$ minute at $35^{\circ} \mathrm{C}$ and monitored at $297 \mathrm{~nm}$.

\section{Quantification of the in vivo samples}

The liquid chromatography-mass spectrometry (LC-MS)/MS method was used to trace the VCR amount in the biological samples. ${ }^{26}$ They consisted of lysed cell suspensions and plasma. These materials were preprocessed by the proteinprecipitation method with acetonitrile, and the supernatant was filtrated through $0.22 \mu \mathrm{m}$ aperture membranes before analysis by LC-MS/MS. The LC-MS/MS system consisted of an Agilent 1200 series rapid resolution liquid chromatography system, which comprised an SL autosampler, SL binary pump, degasser, and an Agilent triple-quadrupole MS. A Diamonsil octadecylsilyl column $(50 \times 4.6 \mathrm{~mm}, 1.8 \mu \mathrm{m}$; Dikma Technologies, Lake Forest, CA, USA) with a corresponding guard column (octadecylsilyl, $5 \mu \mathrm{m}$ ) was used for separation. Every $3 \mu \mathrm{L}$ sample was eluted for 2.5 minutes by mobile phase consisting of methanol and aqueous solution ( $0.01 \%$ formic acid, $10 \mathrm{mM}$ ammonium acetate) $(48 / 52, \mathrm{v} / \mathrm{v})$ at a flow rate of $0.4 \mathrm{~mL} /$ minute at $30^{\circ} \mathrm{C}$.

An MS operating condition was established to detect VCR. Triple-quadrupole MS was carried out under positive electrospray ionization and multiple reaction-monitoring mode. Nitrogen was used as a nebulizer gas. The gas flow was $10 \mathrm{~mL} /$ minute $\left(350^{\circ} \mathrm{C}\right)$ and the pressure was set at $40 \mathrm{psi}$. Voltages of fragmentor potential and collision energy were $176 \mathrm{eV}$ and $50 \mathrm{eV}$, respectively. Ion recording used the parent ion of VCR at m/z 825.5 and the daughter ion of VCR at $\mathrm{m} / \mathrm{z} 765.4$.

\section{Preparation of VCR-OA ion-pair complex}

VCR sulfate $(10 \mathrm{mg}$ ) was dissolved in $0.2 \mathrm{~mL}$ double-distilled water, to which $0.3 \mathrm{~mL}$ of $\mathrm{NaHCO}_{3}$ solution $(2.5 \%)$ was added. After 15 minutes of vigorous vortex in darkness and extraction twice with $1.5 \mathrm{~mL}$ dichloromethane, VCR was collected by removing the organic solution under reduced pressure at room temperature. Finally, the mixture of $15 \mathrm{mg} \mathrm{OA}$ and VCR obtained above were mixed in ethanol/dichloromethane $(3 / 1, v / v)$ under gentle stirring at $30^{\circ} \mathrm{C}$ for 30 minutes. The VCR-OA ion-pair complex was formed after organic solvent was removed under reduced pressure at $35^{\circ} \mathrm{C}$.

\section{Solubility of VCR-OA in water}

VCR-OA was produced according to the method described above, while VCR was obtained by adding excess base to neutralize the sulfate of VCR sulfate and then centrifuging to collect VCR precipitation. Excess amounts of VCR or VCR-OA were dispersed in double-distilled water, and then shaken at $70 \mathrm{rpm}$ at $25^{\circ} \mathrm{C}$ (Suzhou Pui Ying Experimental Equipment, Suzhou, People's Republic of China). Twentyfour hours later, all samples were centrifuged (18,000 $\mathrm{g}$, 15 minutes), and the VCR concentration in the supernatant was determined by HPLC. All the analyses were carried out in triplicate.

\section{Preparation of VCR-OA-SME}

VCR-OA-SME was prepared based on the high-pressure homogenization method. Briefly, VCR-OA (equivalent to $10 \mathrm{mg}$ in VCR sulfate), $200 \mathrm{mg}$ soybean lecithin, $200 \mathrm{mg}$ Solutol HS15 and $1600 \mathrm{mg}$ soybean oil were dissolved in an appropriate volume of ethanol, followed by evaporation to remove the organic solvent, and $0.02 \%$ butylated hydroxyanisole was added as antioxidant. The resultant mixture served as an oil phase, to which $7 \mathrm{~mL}$ of saline containing $5 \mathrm{mg}$ vitamin $\mathrm{C}$ was added drop-wise, followed by an aliquot to $10 \mathrm{~mL}$ with saline and homogenization (Emulsi Flex-C5; Avestin, ON, Canada) ten times at 10,000 psi. The resulting emulsion was filtered through a membrane $(0.45 \mu \mathrm{m})$ to obtain the final VCR-OA-SME formulation.

\section{Characterization of VCR-OA-SME}

Size distribution and zeta potential of VCR-OA-SME

The average particle size and zeta potential of VCR-OASME were measured by dynamic light-scattering (DLS) and electrophoretic light-scattering technology, respectively, with photon correlation spectroscopy (Nano ZS90; Malvern Instruments, Malvern, UK).

\section{Transmission electron microscopy}

The morphology of VCR-OA-SME was examined by transmission electron microscopy. The sample was stained with $2 \%(\mathrm{w} / \mathrm{v})$ phosphotungstic acid before being placed on copper grids with films for transmission electron microscopy (H-600; Hitachi, Tokyo, Japan).

\section{Encapsulation efficiency and drug loading}

The encapsulation efficiency and drug loading of VCR-OASME were determined by ultrafiltration. In detail, after VCROA-SME was prepared as mentioned above, the water phase as well as free drug was separated from the whole system by 
ultrafiltration (molecular weight cutoff, $30 \mathrm{kDa}$ ) at $3075 \mathrm{~g}$ for 70 minutes. The ultrafiltrate was collected and suitably diluted with ethanol to measure the amount of encapsulated VCR (VCR $_{\mathrm{e}}$ by HPLC. In addition, VCR-OA-SME was demulsified with ethanol to determine the amount of total VCR (VCR $)$. The encapsulation efficiency and drug loading of VCR-OA-SME were then calculated by the following equations as:

$$
\begin{gathered}
\mathrm{EE}=\frac{\mathrm{VCR}_{\mathrm{e}}}{\mathrm{VCR}_{\mathrm{t}}} \times 100 \% \\
\mathrm{DL}=\frac{\mathrm{VCR}_{\mathrm{e}}}{\mathrm{VCR}_{\mathrm{e}}+\text { Excipients }} \times 100 \%
\end{gathered}
$$

\section{In vitro release study of VCR-OA-SME}

The drug release from the submicron emulsion was carried out by dynamic dialysis in phosphate-buffered saline (PBS; $\mathrm{pH}$ 7.4). ${ }^{27-29}$ The dialysis bags with a molecular weight cutoff of 8000-14,000 Da were used to retain VCR-OA-SME while allowing the free drug to permeate into the release medium. Briefly, the dialysis bag, loaded with $1 \mathrm{~mL}$ of VCR-OA-SME, was immersed in $4 \mathrm{~mL}$ release medium, followed by shaking in a horizontal shaker protected from light $\left(70 \mathrm{rpm}, 37^{\circ} \mathrm{C} \pm 0.5^{\circ} \mathrm{C}\right)$. The released medium was collected at fixed time intervals $(0.5$, $1,2,4,8,12,24$, and 48 hours) and replaced with $4 \mathrm{~mL}$ of fresh medium. The collected solution was replenished to $5 \mathrm{~mL}$ and kept under $-80^{\circ} \mathrm{C}$ till the analysis by HPLC. As a control, the release pattern of VCR sulfate solution was also studied. All the measurements were carried out in triplicate.

\section{Pharmacokinetic study of VCR-OA-SME}

The healthy adult male Wistar rats, weighing $220 \pm 20 \mathrm{~g}$ (mean \pm standard deviation), were divided randomly into two groups (five rats for each group). At a dose of $1.2 \mathrm{mg} / \mathrm{kg}$ equivalent to VCR, group one and two were intravenously injected with VCR sulfate solution and VCR-OA-SME formulation, respectively. At fixed time points, $300 \mu \mathrm{L}$ of blood was collected from the eye socket into the heparinized tubes. The plasma separated by centrifuge ( $2000 \mathrm{~g}, 5$ minutes) was stored under $-80^{\circ} \mathrm{C}$ until analysis by LC-MS/MS.

\section{In vitro therapeutic effect study}

\section{In vitro cytotoxicity assay}

To compare the in vitro cytotoxicity of free VCR, VCROA-SME, and blank SME, an MTT assay was performed on MCF-7 cells. In short, MCF-7 cells in logarithmic growth phase were seeded in 96-well plates at a density of 6000 cells per well in $100 \mu \mathrm{L}$ culture medium. After 24 hours of attachment, cells were treated with $200 \mu \mathrm{L}$ culture medium containing different concentrations of free VCR, VCR-OA-SME, and blank SME for another 48 hours at $37^{\circ} \mathrm{C}$. Cells exposed to culture medium without VCR served as negative control. Subsequently, the medium was replaced with MTT solution ( $5 \mathrm{mg} / \mathrm{mL}$ ), which was followed by 4-hour incubation. Finally, the MTT solution was removed carefully, and $200 \mu \mathrm{L}$ dimethyl sulfoxide was added to each well to dissolve formazan. After being gently shaken for 15 minutes, the quantity of formazan was measured by microplate reader (Varioskan Flash; Thermo Fisher Scientific) at $570 \mathrm{~nm}$. Cell-survival ratio was calculated according to the following equation:

$$
\text { Cell survival ratio }=\frac{[\mathrm{Abs}]_{\text {sample }}-[\mathrm{Abs}]_{\mathrm{blank}}}{[\mathrm{Abs}]_{\mathrm{control}}-[\mathrm{Abs}]_{\mathrm{blank}}} \times 100 \%
$$

\section{Cell-cycle assay}

A propidium iodide (PI) staining assay was used to determine cell-cycle distributions, as described in previous studies. ${ }^{7,30}$ In brief, MCF- 7 cells $\left(3 \times 10^{5}\right.$ cells per well $)$ in logarithmic growth phase were seeded in six-well plates and incubated for 48 hours at $37^{\circ} \mathrm{C}$. Then, all media were removed and $2 \mathrm{~mL}$ of medium containing different concentrations of free VCR or VCR-OA-SME was added to each well followed by incubation for another 24 hours. Cells exposed to culture medium without VCR served as negative control. Subsequently, the adherent MCF-7 cells were digested and merged with the floating fraction. After being rinsed thrice with PBS, cells were fixed in cold $75 \%$ ethanol for 30 minutes at $4{ }^{\circ} \mathrm{C}$ and washed twice with PBS, after which $0.1 \mathrm{~mL}$ Triton $\mathrm{X}-100$ $(0.1 \%, \mathrm{~V} / \mathrm{V})$ was added to punch on the cytomembrane. Fifteen minutes later, all cells were incubated with ribonuclease A $\left(20 \mu \mathrm{g} / \mathrm{mL}\right.$ at final concentration) at $37^{\circ} \mathrm{C}$ for 30 minutes to digest RNA and then stained with PI $(20 \mu \mathrm{g} / \mathrm{mL}$ at final concentration) at $4^{\circ} \mathrm{C}$ for another 30 minutes in darkness. Finally, cell-cycle distribution was measured by flow cytometry (Cytomics FC500; Beckman Coulter, Brea, CA, USA), and the DNA histogram was analyzed with MultiCycle software (Phoenix Flow Systems, San Diego, CA, USA). For each sample, $1 \times 10^{5}$ cells were collected.

\section{Cell-apoptosis assay}

It is reported that cell-apoptosis induction is one side of VCR cytotoxicity. ${ }^{7-9}$ Therefore, the apoptotic induction ability on MCF-7 cells by VCR solution or VCR-OA-SME was measured qualitatively by DAPI (4'6-diamidino-2-phenylindole) staining and quantitatively by annexin V-FITC and PI doublestaining assay. ${ }^{7,31}$ 
For DAPI staining, after coincubation with VCR formulations $\left(\mathrm{C}_{\mathrm{VCR}}=10 \mathrm{ng} / \mathrm{mL}\right)$ at $37^{\circ} \mathrm{C}$ for 24 hours, MCF-7 cells $\left(3 \times 10^{5}\right.$ cells per well $)$ were fixed with $4 \%$ paraformaldehyde for 15 minutes. Then, DAPI dye solution $(2 \mu \mathrm{g} / \mathrm{mL})$ was added for observation with a fluorescence microscope (XD30-RFL; Sunny Optical Technology, Zhejiang, People's Republic of China). For the annexin V-binding assay, MCF-7 cells in six-well plates $\left(3 \times 10^{5}\right.$ cells per well $)$ were coincubated with VCR formulations $(\mathrm{VCR}=10 \mathrm{ng} / \mathrm{mL})$ at $37^{\circ} \mathrm{C}$ for 24 hours. Then cells floating in the supernatant were combined with the adherent fraction lysed by trypsin $(0.25 \%)$ and washed thrice with PBS. The cells were incubated with annexin V-FITC and PI for another 15 minutes at room temperature in the darkness according to the instructions, and immediately analyzed by flow cytometry (Cytomics FC500; Beckman Coulter).

\section{In vitro cellular uptake study}

In order to explore the mechanism for increased anticancer effect of VCR-OA-SME, an in vitro cellular uptake assay was conducted. This study aimed at comparing the cell-uptake efficiency between free VCR and VCR-OA-SME. Briefly, MCF-7 cells in logarithmic growth phase were seeded in six-well plates at a density of $3 \times 10^{5}$ cells per well in $2 \mathrm{~mL}$ of culture medium. Twenty-four hours later, cells were exposed to free VCR and VCR-OA-SME at VCR concentrations of 10 and $20 \mu \mathrm{g} / \mathrm{mL}$ and incubated for another 4 hours. Afterwards, all medium was removed carefully, cells were washed thrice by cold PBS ( $\mathrm{pH} 7.4,4^{\circ} \mathrm{C}$ ) to stop cell digestion, and free VCR was removed. The cells were trypsinized and collected by washing with PBS and centrifugation (400 $g$, 3 minutes). Subsequently, $0.4 \mathrm{~mL}$ ultrapure water was added to each sample to resuspend cells, which was followed by cell lysis in liquid nitrogen $\left(-196^{\circ} \mathrm{C}\right)$ and $37^{\circ} \mathrm{C}$ water bath repeated five times. No intact cells observed under microscope indicated that all cells were fractured and cell content was released. Twenty microliters of the above cell-fragment suspension was used for protein measurement, using the enhanced bicinchoninic acid protein assay kit, and another $300 \mu \mathrm{L}$ was taken for VCR quantitation by LC-MS/MS. Cell-uptake efficiency was evaluated by the uptake index (UI, ng/mg), which was calculated based on the following equation:

$$
\mathrm{UI}=\frac{\mathrm{C}_{\mathrm{VCR}}(\mathrm{ng} / \mathrm{mL})}{\mathrm{C}_{\text {Protein }}(\mathrm{mg} / \mathrm{mL})}=\frac{\mathrm{C}_{\mathrm{VCR}}}{\mathrm{C}_{\text {Protein }}}(\mathrm{ng} / \mathrm{mg})
$$

In order to identify whether the drug uptake by cells was energy-dependent endocytosis, another experiment was conducted. The UI of MCF-7 cells incubated with VCR solution or VCR-OA-SME $\left(\mathrm{C}_{\mathrm{VCR}}=10 \mu \mathrm{g} / \mathrm{mL}\right)$ at $4^{\circ} \mathrm{C}$ or $37^{\circ} \mathrm{C}$ for 2 hours was detected, and the latter set as the control. Additionally, cells were cultured in medium containing $0.01 \%$ sodium azide for 30 minutes before medium with free VCR or VCR-OA-SME was added for another 2 hours' incubation, and then the UI was also assayed.

\section{Statistical analysis}

All data subjected to statistic analysis were obtained from at least three parallel experiments, and the results were expressed as means \pm standard deviation. Student's $t$-test was used for significance analysis, and $P<0.05$ was the lowest level of significance to value the difference between two groups.

\section{Results and discussion Preparation of VCR-OA ion-pair complex} The formation of ion pairs has been used to enhance the lipophilicity of ionizable drugs by shielding their charge with an oppositely charged ion instead of chemical modifications. ${ }^{32}$ For example, Choi and Park prepared a hydrophobic ion pair composed of leuprolide sodium oleate, which increased the lipophilicity of leuprolide and was good for entrapment into microspheres. ${ }^{33}$ Furthermore, leuprolide-docusate hydrophobic ion pairing was also formed for further sustained-release microparticle preparation. ${ }^{34}$

In order to increase the hydrophilicity of VCR and then encapsulate it in a submicron emulsion, hydrophobic ionpair formation was chosen to be the strategy. VCR is a vinca alkaloid in which there are two ionizable tertiary nitrogen atoms (Figure $1 \mathrm{~B}, \mathrm{pKa}_{1}=11.10 \pm 0.60, \mathrm{pKa}_{2}=7.90 \pm 0.60$ ) After protonation, positively charged VCR can attach to a negatively charged carboxyl group of fatty acid, resulting in a VCR ion-pair complex. Since VCR is generally used for parenteral administration, choosing an injection-acceptable ion-pairing agent with low toxicity is very important. OA $(\mathrm{pKa}=4.78 \pm 0.10)$ is a kind of biodegradable long-chain fatty acid with high biocompatibility. Most importantly, $\mathrm{OA}$ is available for clinical parenteral usage. ${ }^{35}$ In this study, a negatively charged carboxyl group of OA (Figure 1C) attached with the protonized tertiary nitrogen of VCR to form an ion-pair complex, and its long carbon chain could offer the VCR more hydrophobicity.

Normally, the formation of an ion-pair complex usually comes from various coupling forces, such as electrostatic attraction, hydrogen bonding, and hydrophobic interaction. ${ }^{32}$ 
Although solvents with low dielectric constant can contribute to ion-pair formation, the interaction among hydrophobic groups within an ion-pair complex can also be formed in aqueous solutions. ${ }^{36}$ In this study, a mixed solvent composed of dichloromethane and ethanol was used, in which OA was well dispersed and thus the reaction could be facilitated. During the preparation of VCR-OA, excess amounts of $\mathrm{NaHCO}_{3}$ and OA were added to VCR solution (molar ratio of $\mathrm{VCR}: \mathrm{NaHCO}_{3}: \mathrm{OA}$ was $1: 8: 5$ ). To avoid the effect of salt on drug dissolution in the lipid phase, the VCR sulfate was neutralized by $\mathrm{NaHCO}_{3}$, and then extracted by dichloromethane. The obtained VCR-OA was a light-yellow semisolid substance.

\section{Solubility of VCR-OA in water}

Once VCR-OA formed, the hydrophilicity of VCR was supposed to be changed. As a result, the solubility of VCR and VCR-OA in double-distilled water was $734.7 \pm 19.4 \mu \mathrm{g} / \mathrm{mL}$ and $69.0 \pm 9.0 \mu \mathrm{g} / \mathrm{mL}$, respectively. The significant change in solubility of VCR in water demonstrated the formation of an ion pair with OA, which could be favorable for increasing the solubility of VCR in the lipid phase and thus enhancing the entrapment efficiency of VCR in a submicron emulsion.

\section{Preparation and characterization of VCR-OA-SME}

In order to prepare VCR-OA-SME, Solutol HS15 was chosen as a nonionic surfactant, which was developed by BASF ( Ludwigshafen, Germany) and is listed in European Pharmacopoeia. As a pharmaceutical excipient, it has been approved for clinical parenteral use due to its low toxicity in vivo, such as low hemolytic ability, low histamine release, and high physical tolerance.
The data from DLS showed a narrow distribution of VCR-OA-SME with good homogeneous property (Figure $2 \mathrm{~A}$ ). The average size and polydispersity index were $157.6 \pm 12.6 \mathrm{~nm}$ and $0.204 \pm 0.02$, respectively. This size was smaller than conventional emulsion, probably due to the presence of adequate surfactants, which were composed of 2\% Solutol HS15 and 2\% soybean lecithin. Meanwhile, the OA can also act as a coemulsifier. The zeta potential of VCR-OA-SME was $-26.5 \pm 5.0 \mathrm{mV}$. These high values were helpful for the system's stability, due to the electrostatic repelling force among the particles. ${ }^{37}$ The anionic components in soybean lecithin, such as phosphatidylserine and phosphatidic acid, were mainly responsible for the negative charge on the surface of the emulsion drops. ${ }^{20}$ Moreover, the negatively charged OA may serve as a contributor for the zeta potential. Transmission electron microscopy imaging of VCR-OA-SME (Figure 2B) showed that the micron emulsion drops were spherical and uniform in size, ranging from 100 to $300 \mathrm{~nm}$, which was consistent with DLS assay. The average encapsulation efficiency and drug loading of VCR-OA-SME were measured as $78.64 \% \pm 3.44 \%$ and $0.48 \% \pm 0.02 \%(n=3)$, respectively.

\section{In vitro release of VCR-OA-SME}

The dynamic dialysis method was used to evaluate the release behaviors of VCR-OA-SME and VCR solution. As shown in Figure 3, the release rate of VCR-OA-SME was much slower than that of VCR solution, and the release profiles could be divided into two phases, ie, the initial burst-release phase and the sustained-release phase. During the first 8 hours (initial burst-release phase), $63.96 \%$ of drug was released from the VCR solution, while $35.01 \%$ was from VCR-OA-SME. The lower burst release was more beneficial, since the toxicity of VCR was normally associated with extremely high
A

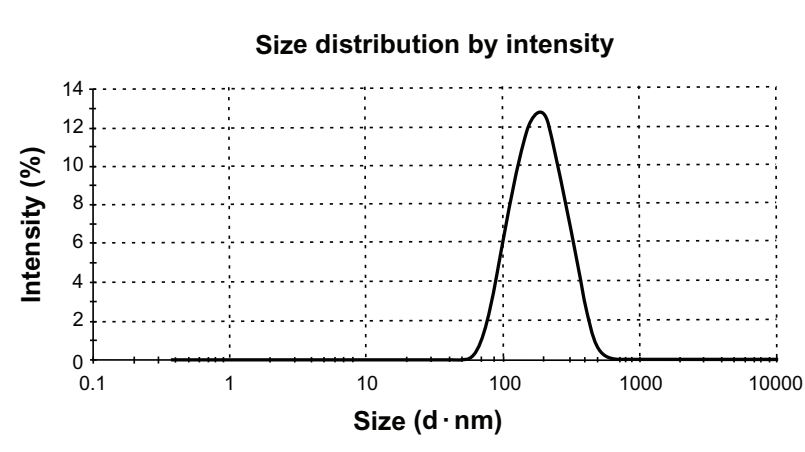

B

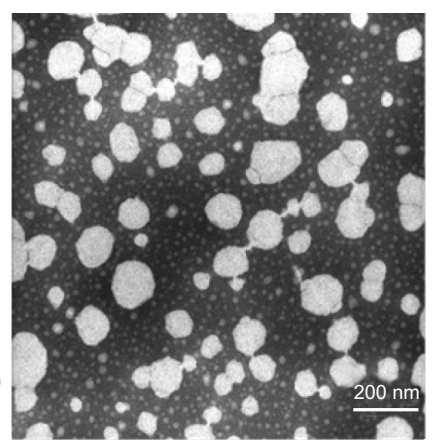

Figure 2 Size distribution of the vincristine-oleic acid ion pair complex-loaded submicron emulsion detected by dynamic light scattering (A) and transmission electron microscopy (B).

Note: (B) Scale bar $=200 \mathrm{~nm}$. 


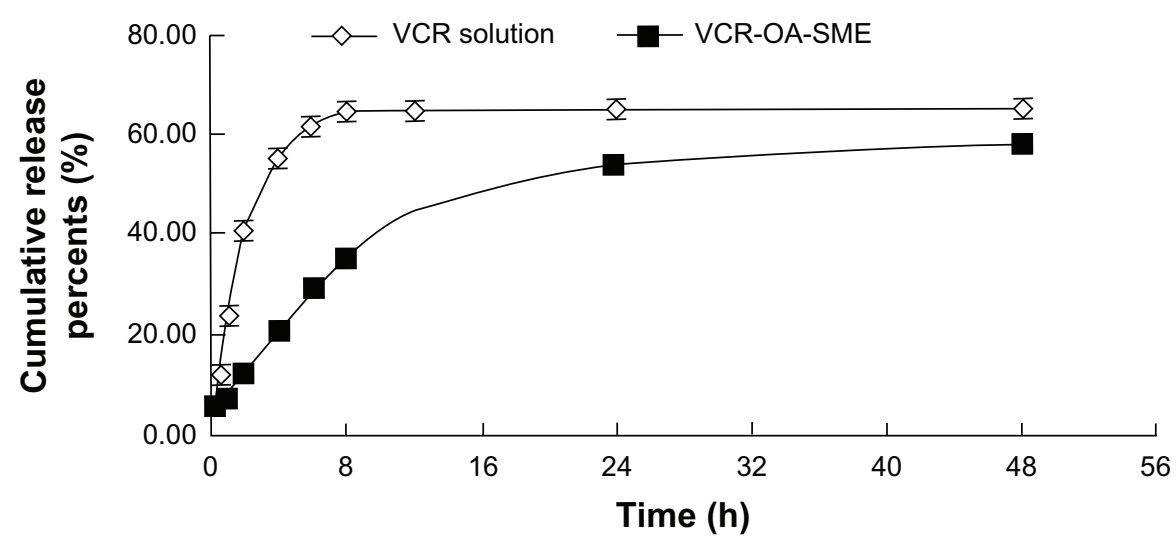

Figure 3 Cumulative release percentages of vincristine (VCR)-time curves.

Notes: In vitro release of VCR from VCR-oleic acid ion pair complex-loaded submicron emulsion (VCR-OA-SME) was assessed by the dynamic dialysis method, as described in the Materials and methods section. Each value represents the mean \pm standard deviation $(n=3)$.

drug concentration. ${ }^{38-42}$ Meanwhile, the higher burst release may cause a higher risk of serious side effects, as well as a lower therapeutic effect. The burst release of VCR-OA-SME may come from the small fraction of drug adsorbed on the surface of the emulsion drops.

\section{Pharmacokinetic study of VCR-OA-SME}

The plasma concentration-time curves of VCR solution and VCR-OA-SME are shown in Figure 4. From this figure, the blood concentration of VCR solution injection is always lower than the VCR-OA-SME, indicating the slower clearance of VCR-OA-SME than VCR solution, which was further demonstrated by the mean retention time value (Table 1). Since VCR is a cell cycle-specific anticancer $\mathrm{drug}^{3-7}$ whose curative effect is time-dependent, longer mean retention time with appropriate drug concentration may have better anticancer effect. ${ }^{43}$ The slower release of VCR from VCR-OA-SME may be one of the main reasons for its slower clearance. In addition, the area under the curve value of VCR-OA-SME is higher than that of VCR solution (Table 1), indicating that VCR-OA-SME has a higher absolute bioavailability. There is no doubt that slower clearance and higher bioavailability

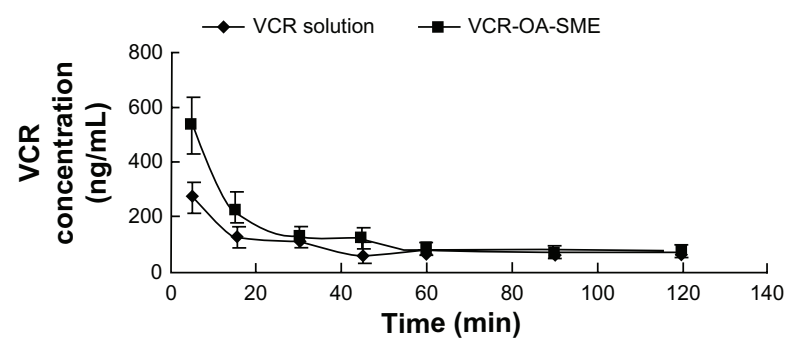

Figure 4 Plasma vincristine (VCR) concentration-time curves after intravenous administration of VCR solution or VCR-oleic acid ion pair complex-loaded submicron emulsion (VCR-OA-SME) in Wistar rats at a dosage of $1.2 \mathrm{mg} / \mathrm{kg}$. Note: Each value represents the mean \pm standard deviation $(n=5)$. are beneficial for higher drug accumulation in tumors and thus for better therapeutic effect.

\section{In vitro therapeutic effect study} In vitro cytotoxicity assay

Cytotoxicity of free VCR, VCR-OA-SME, and blank SME was compared by conducting an MTT assay. As presented in Figure 5, the survival curves of MCF-7 showed a concentration-dependent tendency in the range of 0.1 $0.5 \mu \mathrm{g} / \mathrm{mL}$. The cell-survival rate in the VCR-OA-SME group was significantly lower than that in the free VCR group $(P<0.05)$, demonstrating that VCR-OA-SME showed higher anticancer efficacy than free VCR solution. It is reported that the in vitro cytotoxicity may come from drug property and release profile. ${ }^{44}$ Firstly, VCR-OA-SME can be endocytosed in an intact form due to its small size and the surface charge. Secondly, VCR-OA has a higher hydrophobicity than free VCR and thus has a better affinity to the cell membrane.

In addition, the cell-survival rate in the blank SME group was close to $100 \%$ without correlation with drug

Table I Pharmacokinetic parameters of vincristine (VCR) solution and VCR-oleic acid ion pair complex-loaded submicron emulsion (VCR-OA-SME)

\begin{tabular}{lll}
\hline Parameters & VCR solution & VCR-OA-SME \\
\hline AUC $(0-t)(\mu \mathrm{g} / \mathrm{L} /$ minute $)$ & 11417.77 & $17164.34^{* *}$ \\
AUC $(0-\infty)(\mu \mathrm{g} / \mathrm{L} /$ minute $)$ & 25201.88 & $36855.95^{*}$ \\
MRT $(0-t)$ (minutes) & 48.13 & $36.82^{* *}$ \\
MRT $(0-\infty)$ (minutes) & 187.19 & $227.56^{*}$ \\
$t_{1 / 2 z}($ minutes $)$ & 127.78 & 182.77 \\
$C_{\max }(\mu g / L)$ & 252.13 & $533.34 * *$ \\
\hline
\end{tabular}

Notes: $* P<0.05$; $* * P<0.01$ compared with $V C R$ solution group.

Abbreviations: AUC, area under the plasma concentration-time curve; MRT, mean retention time; $t_{1 / 22}$, elimination half life; $\mathrm{C}_{\max }$, the maximum VCR concentration in plasma. 


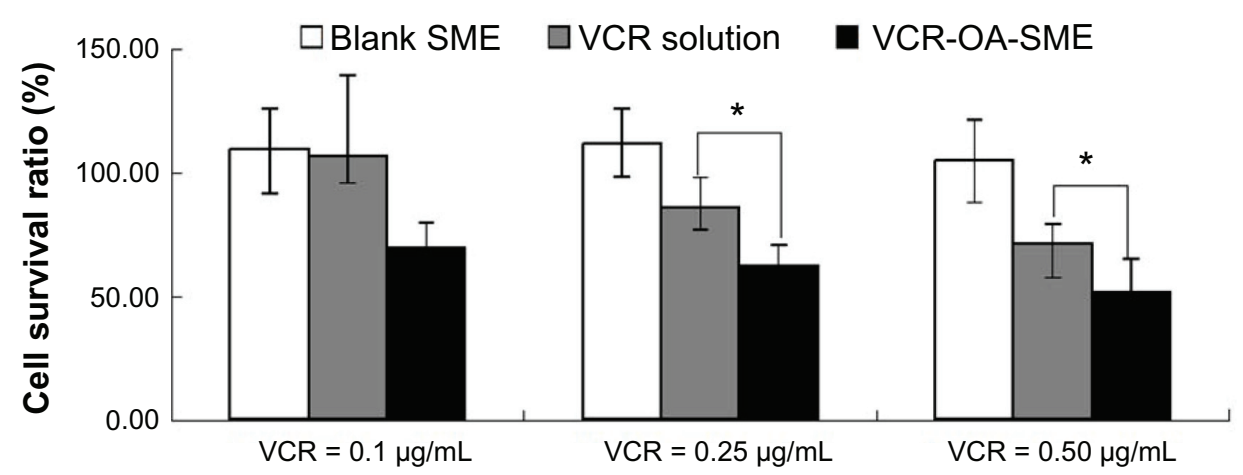

Figure 5 Cell survival-ratio column diagram of VCR formulations on MCF-7 cells by MTT assay.

Notes: $* P<0.05$ compared with VCR solution group. Each value represents the mean \pm standard deviation $(n=3)$.

Abbreviations: VCR-OA-SME, vincristine-oleic acid ion pair complex-loaded submicron emulsion; MTT, 3-(4, 5-dimethyl thiazol-2-yl)-2,5-diphenltetrazolium bromide.

concentrations, indicating that the excipients of VCROA-SME were a nontoxic formulation that can be well tolerated.

\section{Cell-cycle assay}

Many studies have validated that vinca alkaloids, such as vinblastine, VCR, and vinorelbine, can inhibit microtubule assembly and induce tubulin self-association into coiled spiral aggregates, resulting in cells arrested in the $\mathrm{G}_{2} / \mathrm{M}$ phase, ie, antimitotic effects. $3,6,7,45,46$

To estimate the in vitro antimitotic effect of VCROA-SME at the cellular level, the effect of VCR solution and VCR-OA-SME on the cell cycle using MCF-7 cells was evaluated, and the results are presented in Figure 6.
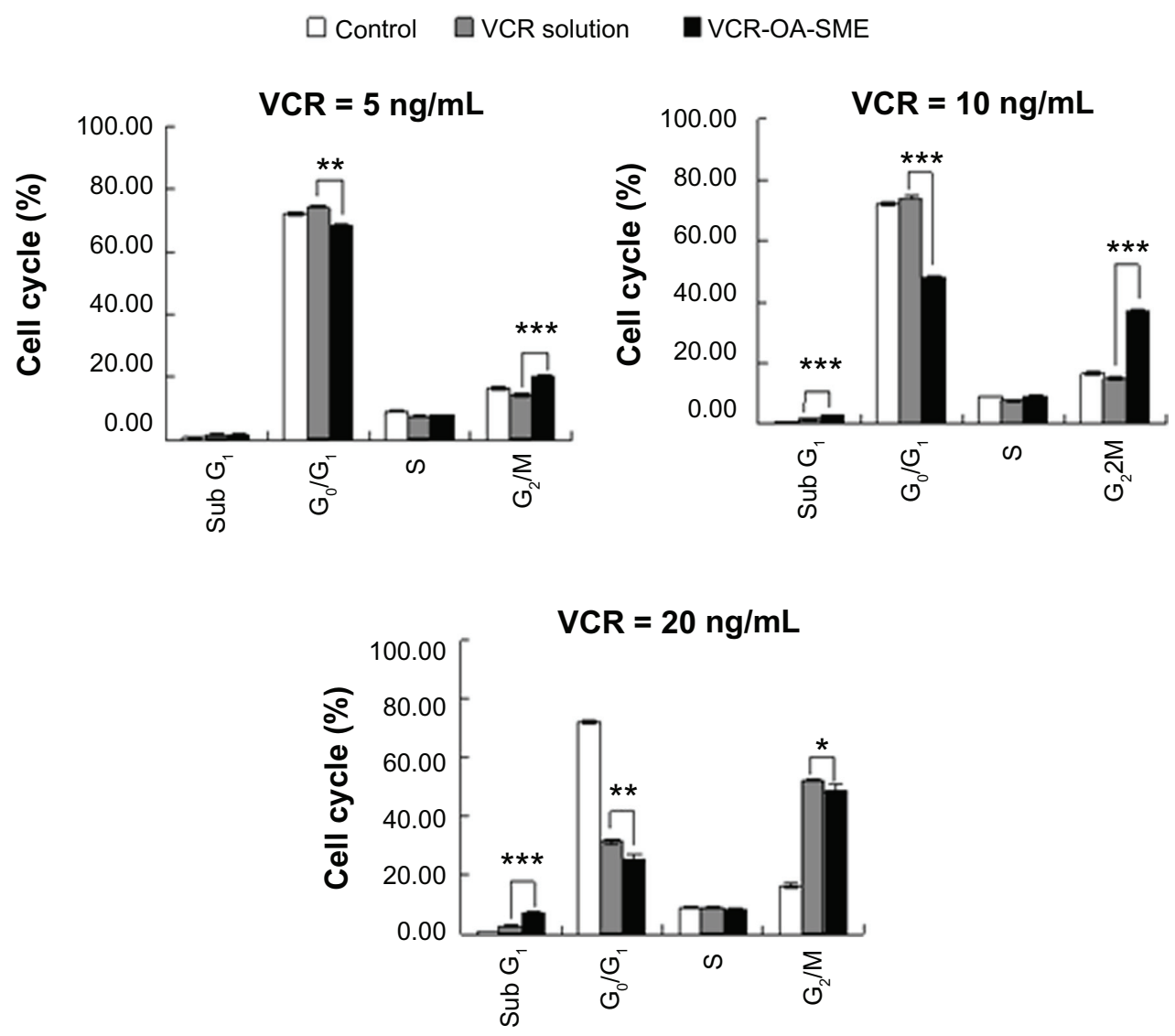

Figure 6 Flow cytometry analysis of cell cycle for MCF-7 cells exposed to different VCR formulations and concentrations.

Notes: $* P<0.05$; $* * P<0.01$ I $* * * P<0.00$ I. Each value represents the mean \pm standard deviation $(n=3)$.

Abbreviation: VCR-OA-SME, vincristine-oleic acid ion pair complex-loaded submicron emulsion. 
In contrast with VCR solution, VCR-OA-SME could arrest more cells in the $\mathrm{G}_{2} / \mathrm{M}$ phase $(P<0.001)$ and fewer cell populations in the $\mathrm{G}_{0} / \mathrm{G}_{1}$ phase $(P<0.01)$ at 5 and $10 \mathrm{ng} / \mathrm{mL}$, indicating that the mitotic activity was inhibited more by VCR-OA-SME. Furthermore, when VCR concentration was 10 or $20 \mathrm{ng} / \mathrm{mL}$, the cell population in the sub- $\mathrm{G}_{1}$ phase in the VCR-OA-SME group was more than that in the VCR solution group $(P<0.001)$. Since the sub- $\mathrm{G}_{1}$ phase is a characteristic hypodiploid DNA content peak indicating apoptotic and necrotic cells, ${ }^{47}$ more cells in the sub- $\mathrm{G}_{1}$ phase in the VCR-OA-SME group mean that VCR-OA-SME could induce more cells to undergo apoptosis. ${ }^{48,49}$ Although MCF-7 exhibited more cells in the $\mathrm{G}_{2} / \mathrm{M}$ phase for the VCR solution group compared with VCR-OA-SME group at $20 \mathrm{ng} / \mathrm{mL}$, more cells were arrested in the sub- $\mathrm{G}_{1}$ phase for the VCR-OA-SME group than in other groups $(P<0.001)$, which indicated that more cell apoptosis was induced after cell-cycle arrest by VCR-OA-SME. ${ }^{30,50}$

\section{Cell-apoptosis assay}

Many previous studies have shown that vinca alkaloids can induce cell apoptosis. ${ }^{7-9,30,47}$ As shown in Figure 7A, the morphology of MCF-7 cells significantly changed after VCR treatment. The cells became partly round, and some of them even floated in the culture medium, and this phenomenon was more obvious in VCR-OA-SME group. It is well known that the apoptotic cell nucleus will show many morphologic modifications, such as nuclear pyknosis and condensation, chromatin fragmentation, and formation of apoptotic bodies. ${ }^{51}$ In Figure $7 \mathrm{~B}$, the morphology of
A

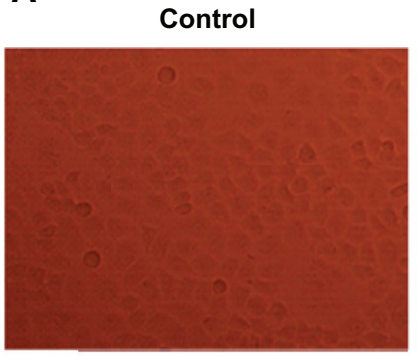

B

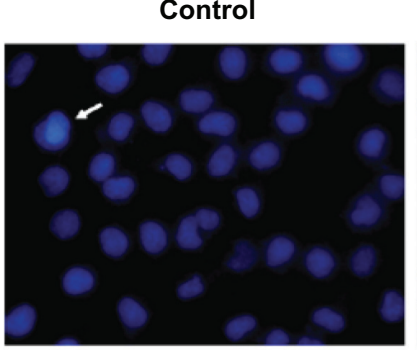

C

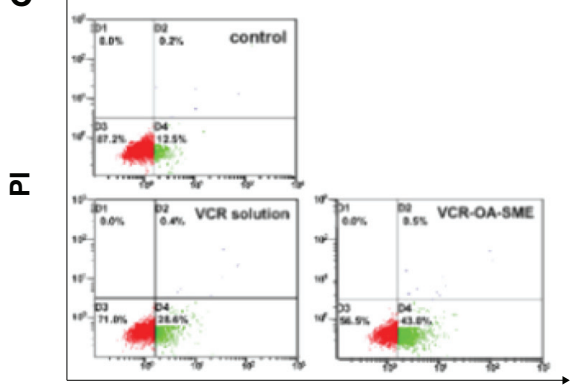

Annexin-V FITC

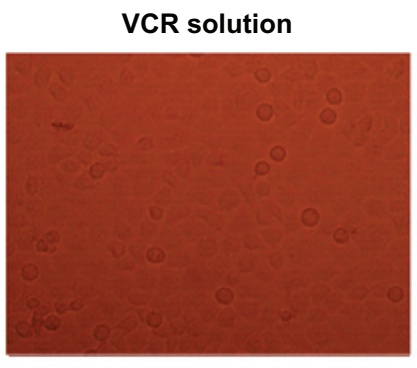

VCR solution

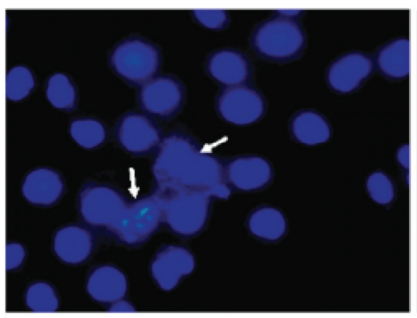

D

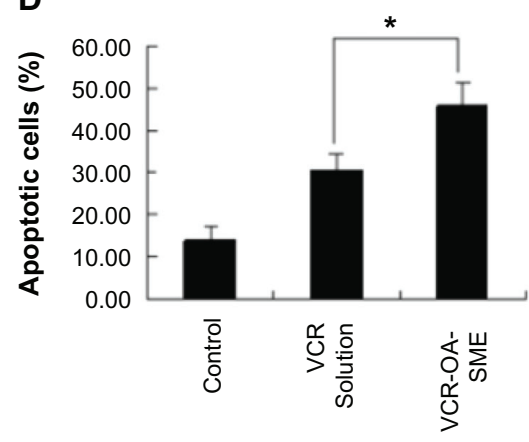

Figure 7 (A-D) Induction of apoptosis by, vincristine-oleic acid ion pair complex-loaded submicron emulsion (VCR-OA-SME) on MCF-7 cells. (A) MCF-7 cell images under microscope after being induced by VCR solution or VCR-OA-SME for 24 hours $\left(C_{\mathrm{VCR}}=10 \mathrm{ng} / \mathrm{mL}\right)$. Scale bar $=200 \mu \mathrm{m}(\mathrm{n}=3)$. (B) DAPI staining of fragmented chromatin or apoptotic bodies in MCF-7 cells after being treated with VCR solution or VCR-OA-SME for 24 hours. Scale bar $=30 \mu \mathrm{m}$ ( $\mathrm{n}=3$ ). (C) Apoptosis assay conducted by flow cytometry with annexin V-FITC in combination with PI. (D) The proportion of apoptosis in MCF-7 cells exposed to VCR solution or VCR-OA-SME for 24 hours analyzed by flow cytometry $\left(\mathrm{C}_{\mathrm{vCR}}=10 \mathrm{ng} / \mathrm{mL}\right)$.

Notes: $* P<0.05$. Each value represents the mean \pm standard deviation $(n=3)$.

Abbreviations: DAPI, 4'6-diamidino-2-phenylindole; FITC, fluorescein isothiocyanate; PI, propidium iodide. 

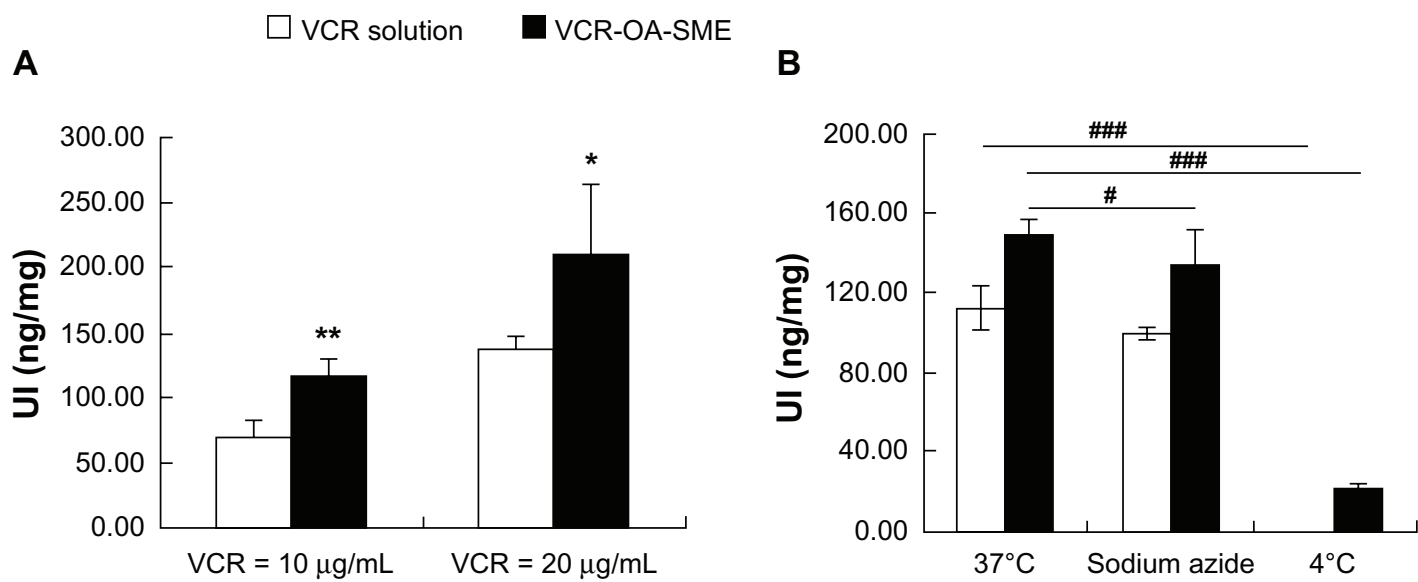

Figure 8 (A and B) The uptake index (UI) of MCF-7 cells exposed to vincristine (VCR) solution or VCR-oleic acid ion pair complex-loaded submicron emulsion (VCR-OASME) under different conditions. (A) Cell UI of MCF-7 cells incubated with VCR solution or VCR-OA-SME containing different concentrations of VCR (I0 $\mu \mathrm{g} / \mathrm{mL}$ and $20 \mu \mathrm{g} / \mathrm{mL}$ ) for 4 hours. $* P<0.05$; $* * P<0.01$; ${ }^{* * * P}<0.001$ compared with VCR solution group $(\mathrm{n}=3)$. (B) Cell UI of MCF-7 cells incubated with VCR solution or VCR-OA-SME $\left(C_{\mathrm{VCR}}=10 \mu \mathrm{g} / \mathrm{mL}\right)$ for 2 hours in $37^{\circ} \mathrm{C}, 4^{\circ} \mathrm{C}$, or pretreated with $0.01 \%$ sodium azide for 30 minutes.

Notes: ${ }^{P} P<0.05 ;{ }^{\# \#}<<0.001$. Each value represents the mean \pm standard deviation $(\mathrm{n}=3)$.

the cell nucleus in the control group was maintained with homogeneous chromatin, while the significant chromatin condensation, nuclear fragmentation, or even apoptotic body formation could be found in the VCR-treated groups. It was also found that the nucleus-morphology change was more severe in the VCR-OA-SME group. In addition, these cell-apoptotic extents were quantified. Cells were stained with annexin-V/PI and the percentages of viable (annexin $\mathrm{V}^{-} / \mathrm{PI}^{-}$), early apoptotic (annexin $\mathrm{V}^{+} / \mathrm{PI}^{-}$), late apoptotic or secondary necrotic (annexin $\mathrm{V}^{+} / \mathrm{PI}^{+}$), and necrotic (annexin $\mathrm{V}^{-} / \mathrm{PI}^{+}$) cells were measured by CellQuest (Becton Dickinson) software (Figure 7C). As a result, VCR-OA-SME could induce more cell apoptosis $(45.80 \% \pm 5.56 \%)$ than free VCR $(30.43 \% \pm 4.07 \%)(P<0.05)$ (Figure 7D), which was consistent with the higher cytotoxicity data of VCR-OA-SME.

\section{In vitro cellular uptake study}

To investigate the causes of increased antineoplastic effect of VCR-OA-SME, an in vitro cellular uptake assay was conducted on MCF-7 cells. As shown in Figure 8A, more VCR was taken up by cells in the form of VCR-OA-SME at $10 \mu \mathrm{g} / \mathrm{mL}(P<0.01)$ and $20 \mu \mathrm{g} / \mathrm{mL}(P<0.05)$ when compared with VCR solution. It was also found that the cell uptake of VCR solution and VCR-OA-SME were concentration-dependent. As presented in Figure 8B, the cell uptake of VCR-OA-SME was significantly restrained at $4{ }^{\circ} \mathrm{C}$ and in the presence of sodium azide, which is a mitochondrial adenosine triphosphatase inhibitor and can inhibit energy metabolism, ${ }^{52,53}$ indicating that the cell uptake of VCR-OASME was both temperature- and energy-dependent. However, the VCR solution uptake by cells incubated at $4{ }^{\circ} \mathrm{C}$ became undetectable $(\mathrm{UI}=0)$, whereas the presence of sodium azide existed, indicating that the uptake of VCR solution was mainly temperature-dependent. The additional cell-uptake pathway of VCR-OA-SME (the energy-dependent cell uptake) may be also one of the reasons for its higher uptake efficiency and cytotoxicity. According to the previous studies on nanomedicine ${ }^{54}$ and the characteristics of VCR-OA-SME (such as size and material composition), endocytosis could be the most likely pathway of VCR-OA-SME taken up by cells in the study.

\section{Conclusion}

In the present work, the encapsulation of VCR was facilitated by formation of an ion pair with OA, and the prepared VCROA-SME had small size and spherical shape. The in vitro release rate of VCR-OA-SME was significantly slower than that of the VCR solution. The in vivo study showed that VCR-OA-SME had a longer mean retention time compared to VCR solution. Furthermore, compared with free VCR, VCR-OA-SME could lead to more cell uptake, arrest more cells in the $\mathrm{G}_{2} / \mathrm{M}$ phase, and induce more apoptosis, and thus showed a higher antineoplastic effect.

In conclusion, VCR-OA-SME has great potential to serve as a potential system for the delivery of VCR with higher antitumor effects. Further study on in vivo anticancer effect is being explored.

\section{Acknowledgments}

This work was supported by grants from the National Basic Research Program of China (973 program, no 2009CB930300), the National S \& T Major Project of China 
(grant no 2012ZX09304004), and the National Natural Science Foundation of China (no 81273443). The authors also thank Alberto Andres Martinez (Herbert Wertheim College of Medicine, Florida International University, Miami, USA) for editorial assistance.

\section{Disclosure}

The authors report no conflicts of interest in this work.

\section{References}

1. Johnson IS, Armstrong JG, Gorman M, Burnett JP Jr. The vinca alkaloids: a new class of oncolytic agents. Cancer Res. 1963;23(8):1390-1427.

2. Gidding CEM, Kellie SJ, Kamps WA, de Graaf SSN. Vincristine revisited. Crit Rev Oncol Hematol. 1999;29(3):267-287.

3. Owellen RJ, Hartke CA, Dickerson RM, Hains FO. Inhibition of tubulin-microtubule polymerization by drugs of the Vinca alkaloid class. Cancer Res. 1976;36(4):1499-1453.

4. Jordan MA, Thrower D, Wilson L. Mechanism of inhibition of cell proliferation by Vinca alkaloids. Cancer Res. 1991;51(8):2212-2222.

5. Lobert S, Vulevic B, Correia JJ. Interaction of vinca alkaloids with tubulin: a comparison of vinblastine, vincristine, and vinorelbine. Biochemistry. 1996;35(21):6806-6814.

6. Lobert S, Frankfurter A, Correia JJ. Energetics of vinca alkaloid interactions with tubulin isotypes: implications for drug efficacy and toxicity. Cell Motil Cytoskeleton. 1998;39(2):107-121.

7. Lu X, Zhang F, Qin L, Xiao F, Liang W. Polymeric micelles as a drug delivery system enhance cytotoxicity of vinorelbine through more intercellular accumulation. Drug Deliv. 2010;17(4):255-262.

8. Harmon BV, Takano YS, Winterford CM, Potten CS. Cell death induced by vincristine in the intestinal crypts of mice and in a human Burkitt's lymphoma cell line. Cell Prolif. 1992;25(6):523-536.

9. Mohammad RM, Diwakaran H, Maki A, et al. Bryostatin 1 induces apoptosis and augments inhibitory effects of vincristine in human diffuse large cell lymphoma. Leuk Res. 1995;19(9):667-673.

10. Wang JP, Kozo T, Tsuneji N, Yoshie M. Pharmacokinetics and antitumor effects of vincristine carried by microemulsions composed of PEG-lipid, oleic acid, vitamin E and cholesterol. Int J Pharm. 2003;251(1-2): $13-21$.

11. Ling G, Zhang P, Zhang W, et al. Development of novel self-assembled DS-PLGA hybrid nanoparticles for improving oral bioavailability of vincristine sulfate by P-gp inhibition. J Control Release. 2010;148(2): 241-248.

12. Waterhouse DN, Madden TD, Cullis PR, Bally MB, Mayer LD, Webb MS. Preparation, characterization, and biological analysis of liposomal formulations of vincristine. Methods Enzymol. 2005;391:40-57.

13. Allen TM, Newman MS, Woodle MC, Mayhew E, Uster PS Pharmacokinetics and anti-tumor activity of vincristine encapsulated in sterically stabilized liposomes. Int J Cancer. 1995;62(2):199-204.

14. Chen J, Li S, Shen Q. Folic acid and cell-penetrating peptide conjugated PLGA-PEG bifunctional nanoparticles for vincristine sulfate delivery. Eur J Pharm Sci. 2012;47(2):430-443.

15. Noble S, Markham A. Cyclosporin. A review of the pharmacokinetic properties, clinical efficacy and tolerability of a microemulsion-based formulation (Neoral). Drugs. 1995;50(5):924-941.

16. Margreiter R. Efficacy and safety of tacrolimus compared with ciclosporin microemulsion in renal transplantation: a randomised multicentre study. Lancet. 2002;359(9308):741-746.

17. Lawrence MJ, Rees GD. Microemulsion-based media as novel drug delivery systems. Adv Drug Deliv Rev. 2012;64 Suppl:175-193.

18. Klang SH, Frucht-Pery J, Hoffman A, Benita S. Physicochemical characterization and acute toxicity evaluation of a positively-charged submicron emulsion vehicle. J Pharm Pharmacol. 1994;46(12): 986-993.
19. Schwarz JS, Weisspapir MR, Friedman DI. Enhanced transdermal delivery of diazepam by submicron emulsion (SME) creams. Pharm Res. 1995;12(5):687-692.

20. Zhao D, Gong T, Fu Y, et al. Lyophilized Cheliensisin A submicron emulsion for intravenous injection: characterization, in vitro and in vivo antitumor effect. Int J Pharm. 2008;357(1-2):139-147.

21. Muchtar S, Almog S, Torracca M, Saettone M, Benita S. A submicron emulsion as ocular vehicle for delta-8-tetrahydrocannabinol: effect on intraocular pressure in rabbits. Ophthalmic Res. 1992;24(3): 142-149.

22. Ishida T, Maedaa R, Ichiharaa M, Irimurab K, Kiwada H. Accelerated clearance of PEGylated liposomes in rats after repeated injections. $J$ Control Release. 2003;88(1):35-42.

23. Ishida $\mathrm{T}$, Masuda $\mathrm{K}$, Ichikawa $\mathrm{T}$, Ichihara $\mathrm{M}$, Irimura $\mathrm{K}$, Kiwada $\mathrm{H}$. Accelerated clearance of a second injection of PEGylated liposomes in mice. Int J Pharm. 2003;255(1-2):167-174.

24. Ishida $T$, Ichihara $M$, Wang $X$, et al. Injection of PEGylated liposomes in rats elicits PEG-specific IgM, which is responsible for rapid elimination of a second dose of PEGylated liposomes. J Control Release. 2006;112(1):15-25.

25. Ishida T, Kiwada H. Accelerated blood clearance (ABC) phenomenon upon repeated injection of PEGylated liposomes. Int $J$ Pharm. 2008;354(1):56-62.

26. Skolnik JM, Barrett JS, Shi H, Adamson PC. A liquid chromatographytandem mass spectrometry method for the simultaneous quantification of actinomycin-D and vincristine in children with cancer. Cancer Chemother Pharmacol. 2006;57(4):458-464.

27. D'Souza SS, DeLuca PP. Development of a dialysis in vitro release method for biodegradable microspheres. AAPS Pharm Sci Tech. 2005;6(2):E323-E328.

28. Liu S, Tong Y, Yang YY. Incorporation and in vitro release of doxorubicin in thermally sensitive micelles made from poly ( $\mathrm{N}$-isopropylacrylamideco-N, N-dimethylacrylamide)-b-poly (D, L-lactide-co-glycolide) with varying compositions. Biomaterials. 2005;26(24):5064-5074.

29. Peng Q, Zhang ZR, Gong T, Chen GQ, Sun X. A rapid-acting, longacting insulin formulation based on a phospholipid complex loaded PHBHHx nanoparticles. Biomaterials. 2012;33(5):1583-1588.

30. Galán-Malo P, Vela L, Gonzalo $\mathrm{O}$, et al. Cell fate after mitotic arrest in different tumor cells is determined by the balance between slippage and apoptotic threshold. Toxicol Appl Pharmacol. 2012;258(3):384-393.

31. Pourroy B, Carré M, Honoré S, et al. Low concentrations of vinflunine induce apoptosis in human SK-N-SH neuroblastoma cells through a postmitotic G1 arrest and a mitochondrial pathway. Mol Pharmacol. 2004;66(3):580-591.

32. Higashiyama M, Inada K, Ohtori A, Kakehi K. NMR analysis of ion pair formation between timolol and sorbic acid in ophthalmic preparations. J Pharm Biomed Anal. 2007;43(4):1335-1342.

33. Choi SH, Park TG. Hydrophobic ion pair formation between leuprolide and sodium oleate for sustained release from biodegradable polymeric microspheres. Int J Pharm. 2000;203(1):193-202.

34. Alcock R, Blair J, O'Mahony D, Raoof A, Quirk A. Modifying the release of leuprolide from spray dried OED microparticles. J Control Release. 2002;82(2):429-440.

35. Pontes-Arruda A. Biological benefits of an oleic acid-rich lipid emulsion for parenteral nutrition. Clin Nutr Supp. 2009;4(1):19-23.

36. Quintanar-Guerrero D, Allémann E, Fessi H, Doelker E. Applications of the ion-pair concept to hydrophilic substances with special emphasis on peptides. Pharm Res. 1997;14(2):119-127.

37. Freitas C, Muller RH. Effect of light and temperature on zeta potential and physical stability in solid lipid nanoparticle (SLN) dispersions. Int J Pharm. 1998;168(2):221-229.

38. Aley K, Reichling D, Levine J. Vincristine hyperalgesia in the rat: a model of painful vincristine neuropathy in humans. Neuroscience. 1996;73(1):259-265.

39. Authier N, Coudore F, Eschalier A, Fialip J. Pain related behaviour during vincristine-induced neuropathy in rats. Neuroreport. 1999;10(5): 965-968. 
40. Weng HR, Cordella JV, Dougherty PM. Changes in sensory processing in the spinal dorsal horn accompany vincristine-induced hyperalgesia and allodynia. Pain. 2003;103(1-2):131-138.

41. Flatters SJ, Bennett GJ. Ethosuximide reverses paclitaxel- and vincristine-induced painful peripheral neuropathy. Pain. 2004;109(1-2): $150-161$.

42. Wolf S, Barton D, Kottschade L, Grothey A, Loprinzi C. Chemotherapyinduced peripheral neuropathy: prevention and treatment strategies. Eur $J$ Cancer. 2008;44(11):1507-1515.

43. Zhang J, Alter N, Reed JC, Borner C, Obeid LM, Hannun YA. Bcl-2 interrupts the ceramide-mediated pathway of cell death. Pro Natl Acad Sci U S A. 1996;93(11):5325-5328.

44. Zhang YF, Wang JC, Bian DY, Zhang X, Zhang Q. Targeted delivery of RGD-modified liposomes encapsulating both combretastatin A-4 and doxorubicin for tumor therapy: in vitro and in vivo studies. Eur $J$ Pharm Biopharm. 2010;74(3):467-473.

45. Owellen RJ, Owens AH, Donigian DW. The binding of vincristine, vinblastine and colchicine to tubulin. Biochem Biophys Res Commun. 1972;47(4):685-691.

46. Stewart ZA, Westfall MD, Pietenpol JA. Cell-cycle dysregulation and anticancer therapy. Trends Pharmacol Sci. 2003;24(3):139-145.

47. Chen YC, Lu PH, Pan SL, et al. Quinolone analogue inhibits tubulin polymerization and induces apoptosis via Cdk1-involved signaling pathways. Biochem Pharmacol. 2007;74(1):10-19.
48. Yuan X, Shan Y, Zhao Z, Chen J, Cong Y. G0/G1 arrest and apoptosis induced by SARS-CoV $3 b$ protein in transfected cells. Virol J. 2005;2:66.

49. Hwang MS, Baek WK. Glucosamine induces autophagic cell death through the stimulation of ER stress in human glioma cancer cells. Biochem Biophys Res Commun. 2010;399(1):111-116.

50. Shu CH, Yang WK, Shih YL, Kuo ML, Huang TS. Cell cycle G2/M arrest and activation of cyclin-dependent kinases associated with low-dose paclitaxel-induced sub-G1 apoptosis. Apoptosis. 1997;2(5):463-470.

51. Emanuele S, Lauricella M, Carlisi D, et al. SAHA induces apoptosis in hepatoma cells and synergistically interacts with the proteasome inhibitor Bortezomib. Apoptosis. 2007;12(7):1327-1338.

52. Vigers GA, Ziegler FD. Azide inhibition of mitochondrial ATPase. Biochem Biophys Res Commun. 1968;30(1):83-88.

53. Gabuzda D, Busciglio J, Chen LB, Matsudaira P, Yankner BA. Inhibition of energy metabolism alters the processing of amyloid precursor protein and induces a potentially amyloidogenic derivative. J Biol Chem. 1994;269(18):13623-13628.

54. Sahay G, Alakhova DY, Kabanov AV. Endocytosis of nanomedicines. J Control Release. 2010;145(3):182-195.
International Journal of Nanomedicine

\section{Publish your work in this journal}

The International Journal of Nanomedicine is an international, peerreviewed journal focusing on the application of nanotechnology in diagnostics, therapeutics, and drug delivery systems throughout the biomedical field. This journal is indexed on PubMed Central, MedLine, CAS, SciSearch $\AA$, Current Contents ${ }^{\circledR} /$ Clinical Medicine,

\section{Dovepress}

Journal Citation Reports/Science Edition, EMBase, Scopus and the Elsevier Bibliographic databases. The manuscript management system is completely online and includes a very quick and fair peer-review system, which is all easy to use. Visit http://www.dovepress.com/ testimonials.php to read real quotes from published authors. 